\title{
Correction to: Traffic Dynamics-Aware Probe Selection for Fault Detection in Networks
}

\author{
Anuja Tayal ${ }^{1} \cdot$ Neha Sharma $^{1} \cdot$ Neminath Hubballi $^{1}$ (D) Maitreya Natu ${ }^{2}$
}

Published online: 26 March 2020

(c) Springer Science+Business Media, LLC, part of Springer Nature 2020

\section{Correction to: Journal of Network and Systems Management https://doi.org/10.1007/s10922-020-09514-3}

The original version of the article unfortunately contained a typo error in the first author name in the author group. The first author name was incorrectly published as 'Anjua Tayal' and the corrected name is 'Anuja Tayal'.

The original article has been corrected.

Publisher's Note Springer Nature remains neutral with regard to jurisdictional claims in published maps and institutional affiliations.

The original article can be found online at https://doi.org/10.1007/s10922-020-09514-3.

Neminath Hubballi

neminath@iiti.ac.in

Anuja Tayal

phd1601101001@iiti.ac.in

Neha Sharma

ms1804101001@iiti.ac.in

Maitreya Natu

maitreya.natu@tcs.com

1 Discipline of Computer Science and Engineering, Indian Institute of Technology Indore, Indore, India

2 Tata Research Development and Design Centre Pune, Pune, India 